\title{
Actin: its cumbersome pilgrimage through cellular compartments
}

\author{
Michael Schleicher • Brigitte M. Jockusch
}

Accepted: 14 April 2008 / Published online: 26 April 2008

(C) Springer-Verlag 2008

\begin{abstract}
In this article, we follow the history of one of the most abundant, most intensely studied proteins of the eukaryotic cells: actin. We report on hallmarks of its discovery, its structural and functional characterization and localization over time, and point to present days' knowledge on its position as a member of a large family. We focus on the rather puzzling number of diverse functions as proposed for actin as a dual compartment protein. Finally, we venture on some speculations as to its origin.
\end{abstract}

Keywords Actin history - Cytoplasmic motility ·

Transcription · Chromatin remodelling ·

Nucleocytoplasmic traffick

\section{Introduction}

A common incident, ubiquitous and frequently observed by the experienced teacher: a student wants to purify protein $\mathrm{X}$ from an eukaryotic organism Y. Sooner or later the undergraduate stares at SDS polyacrylamide gels and is surprised, disappointed, depressed, furious about those horrible actin contaminations that seem to be everywhere. The student does not care about the advisor's soothing explanations: "actin is the most abundant protein", "actin

\section{Schleicher}

Adolf-Butenandt-Institute, Cell Biology and Center for Integrated Protein Science (CIPSM), Ludwig-Maximilians-University, 80336 Munich, Germany

B. M. Jockusch ( $\square)$

Cell Biology Group, Technical University of Braunschweig,

Spielmannstr. 7, 38092 Braunschweig, Germany

e-mail:bmj@tu-bs.de exists as globular monomer (G-actin) in the soluble supernatant", "but it is also sedimentable as filamentous actin (F-actin)". It will be difficult to calm the young scientist down. Looking at these copious amounts of the protein, the student cannot believe

(1) that a long time ago it was a scientific breakthrough to show that actin exists at all,

(2) that it took years and years to convince truculent groups of actin pioneers that a non-muscle cell contains actin as well,

(3) that actin is not a singular and once for all invention in evolution, but is the founder of a large family of isoforms and related proteins, and

(4) that quite a number of these proteins can be found in different subcellular compartments. For example, it has been established as a regular component of both, the cytoplasm and the nucleus; but this perception is the result of a fight that went on for decades.

\section{The dawn: actin as a muscle component}

The first traceable report that described contractile substances in muscle goes back to 1859 and Wilhelm Friedrich Kühne (Kuehne 1859). He belonged to the best known physiologists of his time and coined modern designations like "enzyme" or "myosin". The latter one he described as a substance that could be isolated from frog muscle and forms a contractile clot under certain conditions. Today we would call this clot a contractile pellet, consisting mainly of actomyosin. Halliburton followed shortly afterwards and was intrigued by this clot formation (Halliburton 1887). He compared it to blood clotting and the transformation of fibrinogen to fibrin. In tedious experiments he extracted 
mammalian muscle tissue at different time scales, temperatures, salt concentrations and found that myosin apparently needed an additional component to perform fast aggregation and contraction. Without really knowing it, Halliburton worked with actin and produced with this so-called "myosin ferment" an actomyosin precipitate. In our days one reads Halliburton's publication with some amazement. The report covers 70 pages and looks with its descriptions and tables like a lab-book, e.g.: "Extract \#1-10 a.m.-Diluted with an equal amount of water-10 a.m. next day-No change". Surely, at that time editors were not as busy as they are today.

\section{Muscle actin comes of age}

Then, it took almost 60 years until Brúnó F. Straub in Albert Szent-György's laboratory at the Hungarian University of Szeged was able to purify actin in good qualities and quantities. At that time ATP was known and available, i.e. Straub could study the influence of ATP on the viscosity of myosin preparations in the presence and absence of other extractable muscle components. The decrease in viscosity upon addition of ATP was considered "activation" of myosin, the protein responsible for this activation was named "actin", and the complex of these two proteins was "actomyosin". Straub and Szent-Györgyi discovered these interrelationships 1941/ 1942 in the middle of World War II and, therefore, published the data only in local periodicals ("Studies from the Institute of Medical Chemistry”, University of Szeged). The research on actin and myosin, the political situation and the excitement in Szent-Györgi's group in the early 1940s are nicely summarized by W.F. Mommaerts who was a witness of the original experiments (Mommaerts 1992), and by A.G. Szent-Györgyi himself (Szent-Gyorgyi 2004).

It is far beyond the scope of this review to cover the avalanche of actin and myosin research that started after those first molecular characterizations. Of course, muscle was and still is the major source to purify actin from, and, consequently, the research during the following decades used exclusively muscle actin.

\section{Actin conquers the cytoplasm}

But as it is in science, one opens one door and discovers ten closed ones. Keeping that in mind a scientist should always be suspicious regarding dogmas of all sorts. For some time it was almost a law that actin exists only in skeletal muscle and that the well-known conventional myosin is the only motor protein which turns the world go round. Today it is a common place that both assumptions were wrong, although it was quite a task to convince the scientific community.
Many minor publications pointed at the presence of actin in non-muscle cells. For example, one found actomyosinlike components and $\mathrm{Mg}^{2+} \mathrm{ATP}-$ dependent viscosity changes in extracts from sea urchin eggs (Ohnishi 1962), and an actin-like protein from calf thymus nuclei (Ohnishi et al. 1963), and it was assumed that the filaments seen in fibroblasts are analogous to filaments in muscle, responsible for cell motility (Buckley and Porter 1967). Most of these publications never had a really strong impact, especially since they argued against a rock-solid preconception. But to be fair: these tiny reports were the pebbles that paved the road for better equipped groups and more detailed molecular studies. Notably, it was a slime mould, Physarum polycephalum that was used as a model organism to prove the existence of actin and myosin in non-muscle cells. The key experiments have been performed in Japan, in Sadashi Hatano's group (Hatano and Oosawa 1966a, b; Hatano and Tazawa 1968) and the data were confirmed shortly afterwards by other laboratories. Especially the decoration of actin filaments in non-muscle cells with myosin was a breakthrough technique that unequivocally proved the existence of the actomyosin system in many non-muscle cells (for reviews see: Huxley 1973; Pollard and Weihing 1974; Pollard 1981; Tilney 1975).

\section{Actin as the prototype of a large family}

Today conventional actin is thoroughly studied, with respect to its polymerization and depolymerization equilibrium, its function in the cytoskeleton as a morphological stabilizer, its role during motile activities of a cell, its threedimensional structure, its binding partners, etc. But the traitorous word in this sentence is "conventional". What hides behind "conventional" actin? And what is an actin-related protein?

A "conventional" actin consists of 375 highly conserved amino acids, give or take a few. The polypeptide sequence is folded into a roughly $\mathrm{U}$-shaped molecule, exposing wellcharacterized binding sites for many different ligands. There are several isoforms as products of different genes, coined alpha, beta and gamma actin, all of which are polymorphic proteins capable to form polymers. "Conventional actins" display a particular fold which enables them to interact with a variety of partners, to form specific suprastructures involved in intracellular motility, adhesion and locomotion (see below). Figure 1 shows the dynamics of the actin cortex in a Dictyostelium discoideum amoeba during random migration, pinocytosis, and phagocytosis of a yeast cell. An actin-related protein harbours an actin domain, but it differs from "conventional" actin in size and overall amino acid sequence, usually cannot form polymers and may differ from the conventional form in subcellular 

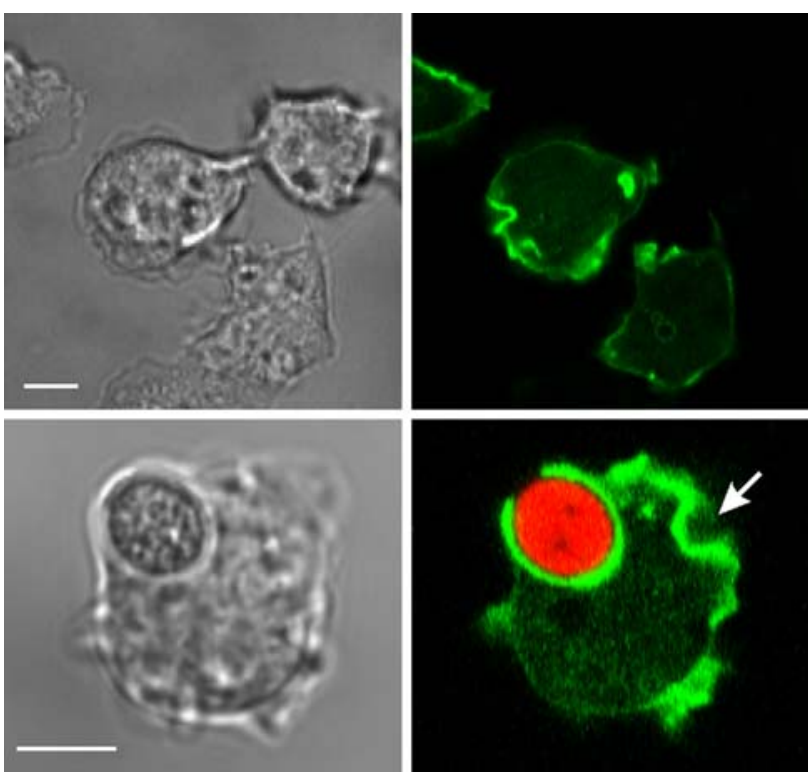

Fig. 1 Dynamics of the actin cortex during amoeboid movement, pino- and phagocytosis. D. discoideum was transformed with a truncated LimE construct, tagged to green fluorescent protein (GFP). LimE binds specifically to filamentous actin (Bretschneider et al. 2004). The transformed cells are depicted in phase contrast (left panels) and fluorescence (right), which reveals the concentration of actin filaments by GFP-LimE. Upper panels: optical section through the actin cortex during random amoeboid movement. Bottom panels: during uptake of a rhodamine-labelled yeast cell the actin cortex forms a phagocytic cup around the particle. The engulfment of liquids by macropinocytosis requires the actin system as well (arrow). Size bar $5 \mu \mathrm{m}$

distribution and its physiological activity. The increasing number of completely sequenced genomes is an enormous help towards our understanding of actin and actin-related proteins. One can take any sequenced genome to analyze actin as a founder of a large protein family. We chose the recently unravelled $D$. discoideum genome since it represents the genome of a model organism that can locomote as a single cell and in cell assemblies, and can differentiate into simple tissues in a developmental cycle. Hence, it is a social amoeba at the evolutionary border between unicellular and multicellular organisms (Eichinger et al. 2005). Notably, the number of actin genes does not tell us very much about the complexity of an organism. Whereas the genome of budding yeast contains only one single and, not surprisingly, essential gene that codes for a conventional actin, mouse harbours 35, and the plant Arabidopsis thaliana 10 actin genes. The $D$. discoideum genome contains 33 genes that code for a bona fide conventional actin. Most puzzling, 17 of these actins share identical amino acid sequences, but are encoded by 17 distinct genes, and many of these are developmentally regulated. Why would evolution allow this seemingly luxurious feature? Elimination of redundant genes can only be avoided if they represent a selective advantage. If the identical actins are translated in a developmental pattern, then posttranslational modifications might play a much larger role than we are aware of today. Indeed, actin's posttranslational modifications are numerous. Actins are acetylated, acylated, arginylated, Ser/Thr/ Tyr-phosphorylated, ubiquitinylated etc. This suggests that a developmentally regulated expression of actin genes requires a similarly regulated expression of enzymes that catalyze posttranslational modifications. Such a hypothesis opens a completely new search for our understanding of actin and its isoforms.

The picture became even more complicated after the discovery of the actin-related proteins (Arps). Calculation of the putative structures shows very nicely that actin and Arps share a common three-dimensional fold (Fig. 2, taken from Muller et al. 2005). Most characteristic is the nucleotide-binding cleft which divides the protein in roughly two halves. The depicted structures all show the same orientation. For actin itself, this means that, when incorporated into a "conventional" actin filament, the bottom part of the folded monomer points towards the fast growing ("barbed") end, the upper part towards the slow growing ("pointed") end (see also Fig. 3). Figure 2 shows strikingly (1) that all Arps can be moulded into a structure quite similar to the overall structure of conventional actin and (2) that they display a clearly distinct pattern of patches with conserved amino acids. As seen in the comparative scale (Fig. 2, right) Arps 1, 2 and 3 are most closely related to actin, whereas all the other Arps show a much lower percentage of identity. Arps 2 and 3 have been shown to form a tight complex that, after activation through several actin binding proteins and ATP, binds to actin filaments and induces their branching (Kiselar et al. 2007). However, it should be noted that the role of the Arp2/3 complex for branching of actin filaments in vivo is still heavily challenged (Koestler et al. 2008). It is quite amusing to read Vic Small's statement in the Research Roundup of $J$ Cell Biol: (Feb 25, 2008): "We haven't disproven branching yet. We'll need 3D imaging to put the nail in that coffin. But what we've seen makes the branching model unlikely". Undoubtedly, we are still on thin ice with our knowledge on Arp2/3 function in vivo.

Let us risk some sort of a heretical view. Trivial as it may be, one has to repeat it again and again: not the threedimensional fold, but the surface of a protein determines its function. There are curious examples for this. Hisactophilin, a histidine-rich actin-binding protein from $D$. discoideum, has a structure nearly identical to that of interleukin$1 \beta$ and fibroblast growth factor, despite its unrelated amino acid sequence. Luckily for the authors, these data were published in a high ranking journal (Habazettl et al. 1992), although there was no functional similarity between these three proteins whatsoever. Today, their structural similarity is not considered important at all and, like many others, 
Fig. 2 Structural conservation in the ARP subfamily (adapted from Muller et al. 2005, with permission). The conservation scale weights identity from 0 (blue) to $100 \%$ (red). All Arps can adopt a global actin conformation (upper left) but only Arps 1,2 and 3 show a pronounced sequence homology
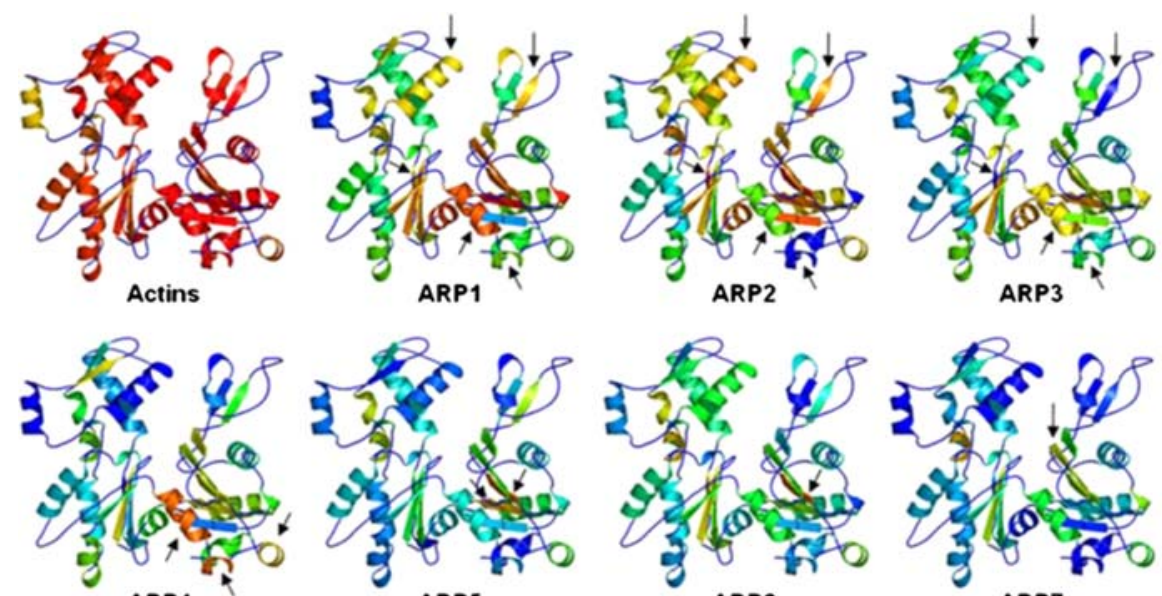

ARP7
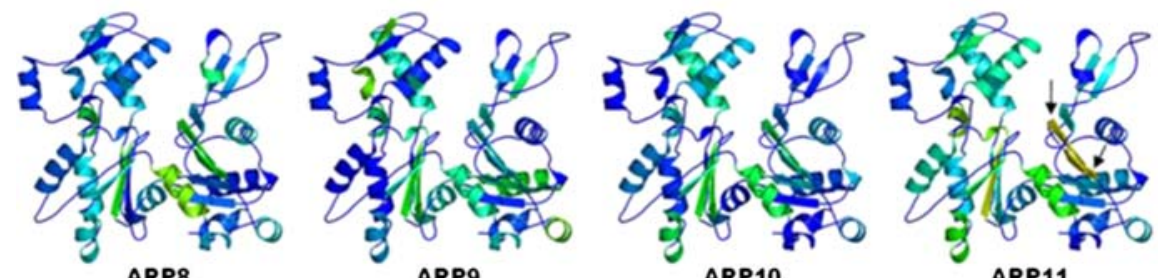

ARP11 they are just members of the large trefoil protein superfamily (Liu et al. 2002). Sippl and coworkers systematically analyzed novel proteins based on known structures (Koppensteiner et al. 2000). They came to the conclusion that almost $30 \%$ of the studied proteins have similar structures but different functions.

Coming back to actins and Arps. Is it possible that the name "actin" for all of these proteins is utterly misleading? Are we wasting time in our search for cytoskeleton-related activities just because the fold triggered a wrong name? Is the so-called actin fold another example for a successful superfamily which contains only a few proteins that play a role in the cytoskeleton, while many other members are e.g. subunits of larger protein complexes in chromatin or hexokinases or proteins with yet unknown functions?

\section{Actin-like proteins in the nucleus: the early period}

The first reports on actin as a nuclear protein appeared already 5 years after its acceptance as a ubiquitous cytoplasmic component. Nuclear filament bundles resembling microfilaments were observed in oocytes when transcription was inhibited by actinomycin D (Lane 1969), and biochemical analyses identified a prominent protein present in isolated nuclei of the multinucleated plasmodia of Physarum polycephalum (Jockusch et al. 1971; Jockusch et al. 1974; Lestourgeon et al. 1975). The concentration of actin in the nucleus fluctuated with the cell cycle phase of the plasmodia, leading to suggestions that nuclear actin might either have a role in the constriction of the nuclear mem- brane in Physarum plasmodia that exhibit an intranuclear mitosis (Jockusch et al. 1971), or with changes in transcriptional activity during the cell cycle (Lestourgeon et al. 1975), or during transition from active growth to the formation of sklerotia (spherules) from plasmodia after starvation (McAlister et al. 1977). All this remained speculation at that time, and the majority of the cell biological community dismissed these findings as an artifact, caused by a contamination of nuclei with cytoplasmic actin. However, between 1979 and 1984 three reports appeared which supported the concept of actin being involved in transcription: (1) actin was identified in a complex of RNA polymerase II from Physarum (Smith et al. 1979), (2) it stimulated markedly the transcriptional activity of RNA polymerase II purified from HeLa cell extracts at the preinitiation phase (Egly et al. 1984), and (3) antibodies specific for actin, when injected into the large amphibian oocyte nuclei, caused a dramatic collapse of lampbrush chromosome loops, concommitant with a complete stop of mRNA transcription (Scheer et al. 1984). However, these observations still did not overcome the scepticism at that time-it took another two decades to recognize actin as a dual compartment protein that can execute different functions by selectively associating with ligands specific either for the cytoplasm or the nucleus.

\section{Actin and Arps in the nucleus}

In the last 20 years, studies on nuclear actin became fashionable, and now a new area began which firmly estab- 


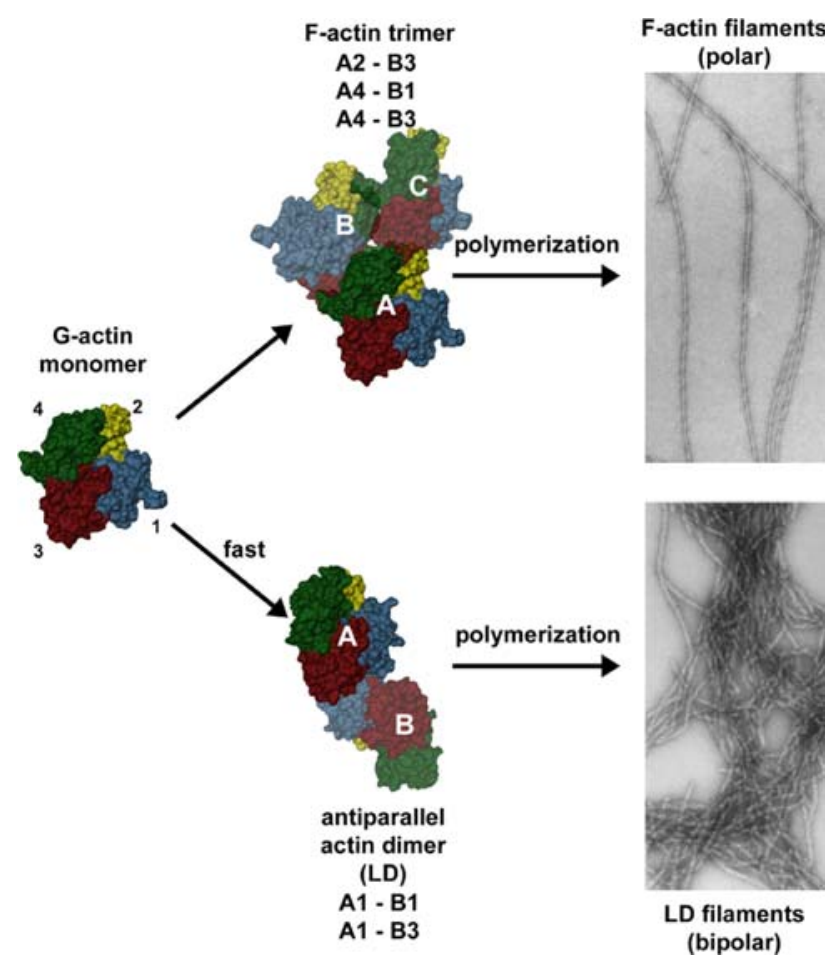

Fig. 3 Generation of different actin polymers as a result of different subunit interactions (adapted from Jockusch et al. 2006, with permission). The subdomains of the actin monomer, as deduced from the crystal structure, are numbered $1-4$. In the process that leads to the "conventional" actin filament (F-actin), three such monomers (a-c) form intermolecular contact sites involving the subdomains as indicated left of the trimeric seed. Under physiological conditions, these trimers convert subsequently into the polar F-actin filaments that are depicted in the electron micrograph (top right). In a more rapid process, the actin monomers may form an antiparallel dimer which, at least in vitro, can form bipolar filaments (LD filaments) that show a strikingly different appearance in the electron microscope (bottom right)

lished actin, its relatives and binding partners as nuclear components.

Several important steps served as signposts in this process:

(1) Cell biologists began to understand that proteins are not necessarily confined to a single intracellular compartment. Numerous examples proved that proteins may shuttle between intracellular regions and even adopt different, compartment-specific activities. Shuttling of actin and actin-related proteins between the nucleus and the cytoplasm cannot be considered any longer as an exceptional, exotic behaviour.

(2) Genetic studies, for example performed with yeast or Drosophila, showed that activities specific for the nucleus, like chromatin remodelling or transcription required the presence of the beta actin isoform, in a configuration that could bind to nuclear protein complexes, but were inhibited with actin mutants that failed in this respect.
(3) The development of cell biological and immunological methods over the past 20 years, like cellular expression of flurorochrome-tagged proteins in conjunction with video microscopy, and the generation of epitope-characterized monoclonal antibodies allowed to follow actin trafficking throughout the cell and its location in the nucleus.

(4) And finally, some old observations made in structural biology came back into people's mind: actin is a highly polymorphic protein, which can give rise to several different and distinct polymers (Aebi et al. 1981; Millonig et al. 1988). Thus, while there are functionally quite unrelated proteins that may share the same structure (see above), it is also conceivable that a particular protein may adopt slightly different "unconventional forms", possibly induced by specific binding partners. Such "distortions" may then trigger the formation of specific oligomers or polymers and complex formation with still other partners. Thus, intranuclear actins need not necessarily adopt the same structures found so abundantly in the cytoplasm, like G- or F-actin. This topic is discussed in detail in (Pederson and Aebi 2002), and this concept is supported by monoclonal anti-actins that specifically decorate nuclear actin (Gonsior et al. 1999; Schoenenberger et al. 2005). In Fig. 3 (taken from Jockusch et al. 2006), we show actin in two different forms that both can form polymers. The conventional actin filament requires the interaction of three actin monomers in a specific orientation. Such a trimeric seed will then grow into the polarized F-actin filaments (Fig. 3, top). However, there is also evidence for another pathway: two actin monomers can bind to each other in another orientation, and this "lower dimer" may then lead to nonpolar, quite different filaments (Fig. 3, bottom). It is of course tempting to speculate that such "unconventional" actin polymers may play a role in vivo, for example in the nucleus, but so far, there is no solid evidence for this assumption.

Not surprisingly, the wealth of data on nuclear actin and its relatives stimulated numerous hypotheses on their function. The relevant findings and the conclusions on putative functions are the topic of a number of interesting reviews, and in this article, we can only refer the reader to them and to the list of original references covered there (Bettinger et al. 2004; Blessing et al. 2004; Franke 2004; Jockusch et al. 2006; Pederson and Aebi 2002; Rando et al. 2000). The brave reader who works himself through all this information will arrive at two conclusions: the actin-like proteins have definitely conquered a firm position among the group of respectable, important nuclear proteins, and they seem to be involved in a plethora of different activities. While the tasks for actin in the cytoplasm all are connected with the 
conventional G- and F-actin structures and the dynamic equilibrium between these two states, nuclear functions of these proteins seem associated with several different forms or configurations which are ill or even not at all defined.

In the following paragraphs, we will briefly mention the most important tasks proposed for nuclear actins.

Actin filaments and a caryoskeleton

It is generally accepted that nuclear activities require a precise topographical arrangement of chromatin, to spatially separate hetero- from euchromatin and allow for the complex mechanism of chromatin remodelling during gene activation and transcription. Hence, when electron microscopy provided elegant images of networks of intranuclear filaments, preferably in large objects like the amphibian oocyte nuclei (germinal vesicles), it seemed quite plausible to conclude that a "nuclear matrix" or scaffold is composed of F-actin filaments (Clark and Merriam 1977; Clark and Rosenbaum 1979; Gard 1999) that could provide mechanical stability to the nucleus and serve as a platform to anchor, at least temporarily, chromatin constituents. Indeed, there is evidence from both earlier and more recent investigations that actin associates with filamentous structures: actin antibodies and myosin subfragment 1 decorate such filaments in amphibian oocyte nuclei (Clark and Rosenbaum 1979; Gard 1999; Scheer et al. 1984), and fluorescently labelled actin is found in a polymeric form in Xenopus and HeLa cell nuclei (Kiseleva et al. 2004; McDonald et al. 2006). Yet, in general, these filaments do not stain with fluorescent phalloidin, a small drug binding with high affinity to actin filaments of the conventional "F-actin" type. It is only after subjecting cells to stress or fixation protocols that nuclear filaments bind phalloidin, thus, the suspicion arises that such treatments rearrange actin into conventional filaments (Gall 2006; Jockusch et al. 2006). This, of course, does not preclude the concept that actin participates in a nuclear matrix, especially in the very large, actin-rich nuclei of amphibian oocytes. There is good evidence that it engages in providing mechanical support to this cellular compartment (Bohnsack et al. 2006; Stuven et al. 2003).

The nuclear Arps from yeast, Arp 7 and Arp 9, have been shown to build heterodimers and have the potential to form filaments from tetramers (Szerlong et al. 2003). However, it is not clear whether they do in vivo, and whether they might coassemble with nuclear actin in polymers (Blessing et al. 2004).

Actin/Arps and their connection with the nuclear envelope

Several structural proteins that are essential for the assembly and maintenance of an intact, functional nuclear enve- lope and its underlying lamina, display well defined binding motifs for actin. These include spectrin, protein 4.1, the nesprins, lamin A and emerin, (Krauss et al. 2003; Shumaker et al. 2003, more references in Blessing et al. 2004; Rando et al. 2000). Hence, it has been speculated, but not proven, that at least part of the nuclear actin is involved in the structural organization of the nuclear envelope.

Actin/Arps and the nucleo-cytoplasmic traffic

Actin-containing, intranuclear filaments were seen to connect to nuclear pore complexes in the amphibian oocyte nucleus (Hofmann et al. 2001; Kiseleva et al. 2004). In the Xenopus oocyte, but also in dipteres and mammalian cells, actin is engaged in the transport and nucleocytoplasmic export of mRNA (Hofmann et al. 2001) and RNA-protein complexes, in particular in those containing a subset of hnRNPs (Percipalle et al. 2001, 2002, reviewed in Bettinger et al. 2004; Pederson and Aebi 2005).

\section{Actin/Arps and chromatin remodelling}

Actin and nuclear Arps were both reported as being critically involved in chromatin remodelling (reviewed in (Bettinger et al. 2004; Blessing et al. 2004; Olave et al. 2002; Percipalle and Visa 2006; Rando et al. 2000). Chromatin remodelling complexes operate as large, multiunit machines in mammals, insects, yeast and plants to reorganize the genetic material by unravelling nucleosomes and converting the genetic material into a form suitable for transcription. Many of these steps require energy, and thus many of these protein complexes contain ATPases, comprised of several subunits, that can be grouped into subfamilies. Actin was identified in complex with specific subunits of most ATPases, together with four nuclear Arps (4, 5, 6 and 8 ) in all organisms, with the exception of yeast. Here, the two yeast-specific nuclear Arps (7 and 9) are found in the corresponding ATPases. One of the histone acetyl transferases that also contribute to chromatin remodelling and subsequent transcription (NuA4, Doyon et al. 2004) is highly conserved from yeast to man and is also found in a complex with actin and Arp 4 (Harata et al. 2002). Structural organization and function of the actin and Arp molecules in these ATPase and acetyl transferase complexes are largely unknown, and speculations for their respective roles range from stabilizing the enzymatic and a chaperoning activity to connecting these gigantic protein complexes to nuclear filamentous scaffolds.

Actin/Arps and transcription

Actin has been identified as a regular component of all the three nuclear RNA polymerases (Pol I, II and III), appa- 
rently interacting with two subunits that are shared among all three enzyme complexes. In vitro transcription by all three enzymes is actin-dependent (reviewed in Grummt 2006; Percipalle and Visa 2006). In the nucleus, pre-mRNA is complexed with ribonucleoproteins to form hnRNPs, and, presumably, there is co-translational recruitment of beta actin to these particles during their formation, as deduced from findings that several hnRNP components bind directly actin. Actin's association with the RNA polymerases may precede, be simultaneous with or follow the initiation of actin-dependent chromatin remodelling by ATP-dependent complexes and/or histone acetylation, as described above (Grummt 2006; Percipalle and Visa 2006). Most of the data available today are derived from studies with Pol II, in insects and vertebrates, supporting and confirming the conclusions drawn more than two decades earlier from work on Xenopus oocyte and HeLa cell nuclei (Egly et al. 1984; Scheer et al. 1984). There is solid evidence that actin's role in Pol II-dependent transcription is executed by the beta actin isoform (Hofmann et al. 2004; McDonald et al. 2006), and no other isoform seems involved. While actin's contribution to the formation of pre-initiation complexes and subsequent transport of premRNPs through the nucleus towards their export through nuclear pores is well accepted today (Bettinger et al. 2004; Franke 2004), it is completely unknown whether actin might mediate such intranuclear movements in filamentous or even contractile structures (Pederson and Aebi 2005).

Actin ligands in the nucleus

The nuclear constituents harbouring actin, like those of the nuclear matrix, the nuclear envelope, the nuclear pores, chromatin remodelling complexes, RNA polymerases and pre-mRNPs are all highly insoluble, gigantic structures. However, there are also actin ligands that are found in the cytoplasmic as well in the nuclear compartment, possibly in rather dynamic and temporary complexes with actin. Since the discovery of actin as a prominent component in the cytoplasm of practically all eukaryotic cells, a plethora of such actin-binding proteins has been described and characterized. They arrange actin into the various suprastructures required for cytoplasmic functions, such as intracellular motility and locomotion, by either regulating the balance between monomeric and filamentous actin, or generating networks and bundles of filaments (Winder and Ayscough 2005). Remarkably, many of these actin ligands are evolutionary well conserved, like actin itself (Korn 1982; Schleicher et al. 1988). Members of the various subfamilies, with affinity to either monomeric or filamentous actin, are dual compartment proteins that can shuttle between the nucleus and the cytoplasm, their main location frequently being dependent on the differentiation state of cells. Comprehen- sive lists of these proteins that have previously been described as cytoplasmic actin ligands but were also identified in the nucleus are given in (Rando et al. 2000; Bettinger et al. 2004; Pederson and Aebi 2005). Among them are several which form complexes with actin and interfere with the formation of conventional actin filaments, like profilin, binding to monomeric actin, and cofilin, a ligand for both, monomeric and polymeric actin. Nuclear profilin is apparently involved in the regulation of the level of nuclear actin, as profilin-actin complexes are recognized and exported from mammalian nuclei by a specific exportin (Stuven et al. 2003), while actin free of profilin can apparently be exported by a different exportin, due to its nuclear export sequences (Wada et al. 1998). Profilin and cofilin both can sligthly change the fold of actin. Profilin induces a form which faciliates the exchange of bound ATP in G-actin (reviewed in Jockusch et al. 2007). Cofilin, a phosphoprotein, contains a nuclear location sequence, and in its dephosphorylated state can transport actin "piggy-back" into the nucleus (Pendleton et al. 2003). When bound to actin polymers, it distorts their conformation such that these filaments do not bind phalloidin anymore. Thus, these proteins might be critical in creating forms specific for nuclear actin, as detected by specific antibodies (Gonsior et al. 1999; Jockusch et al. 2006; Schoenenberger et al. 2005). Among the actin ligands solely found in the nuclear compartment are a nuclear actin binding protein identified in Acanthamoeba (Rimm and Pollard 1989), an actin binding protein composed of two different subunits in mammalian cells (Ankenbauer et al. 1989), and a nucleus-specific form of myosin I (Pestic-Dragovich et al. 2000). The latter is a small, monomeric myosin that does not form filaments as would be needed for contraction of putative actin filaments in the nucleus. It is apparently involved in transcription of ribosomal genes by Pol I, where it binds to a transcription initiation factor but also to components of a chromatin remodelling complex. It has been speculated that in this location it may recruit actin associated with Pol I to the site of rRNA transcription, but so far, there is no evidence that these two proteins interact directly in vivo (reviewed in (Grummt 2006; Percipalle and Farrants 2006).

\section{Conclusions}

So, have we now lost the student being confronted with actin for the first time in his scientific education, or have we been able to attract his curiosity for this abundant, highly conserved, mysterious protein?

Actin has come a long way from the times of its discovery in muscle and we have learned to know it as a member of a large family of structurally related proteins, some of which are dual compartment proteins. Concomitant with 


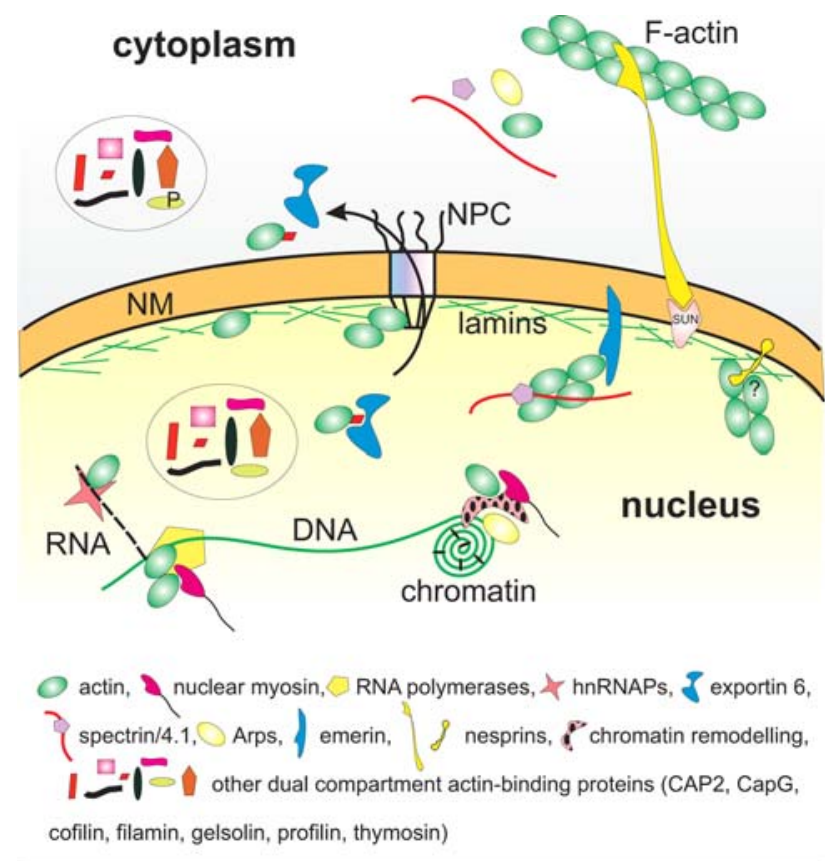

Fig. 4 The manifold functions of nuclear actin. The G-/F-actin equilibrium is only a highly specialized function of actin in the cytoplasm (top); in the nucleus (bottom) the actin system plays a quite different regulatory and structural role. Actin can execute its tasks as monomer or as nucleus-specific polymer. It interacts with heterogenous ribonucleoproteins (hnRNPs) and is thought to function as a track for RNA transport through NPCs. It remains to be shown how nuclear actin cooperates with nuclear myosin-1 to enhance movement of RNA polymerases or to re-organize chromatin (Nunez et al. 2008). Positioning of the nucleus in the cell is achieved by nuclear membrane (NM) proteins that, like the large nesprins, hook the nucleus to the actin cytoskeleton. Anchorage of nesprins is guaranteed by SUN proteins in the inner nuclear membrane (Worman and Gundersen 2006). The stabilization of the nucleoskeleton involves the interaction of inner nuclear membrane proteins like emerin or nesprins with lamins as well as polymeric actin (Libotte et al. 2005). It should, however, be borne in mind that the level of nuclear actin is apparently tightly regulated in mammalian cells by exportin 6 which selectively transports profilin-actin complexes from the nucleus into the cytoplasm (Bohnsack et al. 2006). The nuclear functions of many dual compartment actin binding proteins are not well understood, but one has to assume that their interaction can discriminate between nuclear and cytoplasmic actin (Pederson and Aebi 2005). For example, the recently described cyclase associated protein CAP2 is nuclear in myoblasts but sarcomeric in myotubes (Peche et al. 2007). Actin-related proteins are only summarized in one symbol and are either nucleus specific subunits in chromatin remodelling complexes (Arp4, Arp8 etc.), cytoplasmic or belong also to the group of dual compartment proteins

this, there is an overwhelming expansion of their putative functions, and both, the fine structural conformation as well as the different functions are probably determined by the numerous actin binding proteins. As a cartoon, Fig. 4 summarizes the most important players in the cytoplasmic and the nuclear compartment. It is obvious that the putative activities in the nucleus outnumber those in the cytoplasm. Taken together, these findings allow for the view that actin and its relatives were originally engaged in nuclear activities, and that their appearance in the cytoplasm is related to a specialization in functions connected solely with intracellular motility and locomotion (F-actin filament formation, actin dynamics). Further functional narrowing would then result in the special case of skeletal muscle, where a specific isoform, alpha actin, is overexpressed and knows nothing else than to allow myosin-driven contraction.

If one was to speculate further, one might imagine that prokaryotic precursors of present days' actin, related to the proteins that spatially and temporally control macromolecular trafficking, chromosome segregation and cell polarity in recent bacteria (Carballido-Lopez 2006), appeared first as "nuclear actin" in an ancestor eukaryotic cell as part of the endosymbiontic engulfment. But, it will require several decades and lots of industrious students to decide whether this is science fiction or facts about actin.

Acknowledgments The authors would like to thank the Deutsche Forschungsgemeinschaft (German Research Council) for continuous and generous financial support of their research on actin-based cellular functions, and gratefully acknowledge help from Petros Batsios and Meino Rohlfs (Munich) with Fig. 1.

\section{References}

Aebi U, Fowler WE, Isenberg G, Pollard TD, Smith PR (1981) Crystalline actin sheets: their structure and polymorphism. J Cell Biol 91:340-351

Ankenbauer T, Kleinschmidt JA, Walsh MJ, Weiner OH, Franke WW (1989) Identification of a widespread nuclear actin binding protein. Nature 342:822-825

Bettinger BT, Gilbert DM, Amberg DC (2004) Actin up in the nucleus. Nat Rev Mol Cell Biol 5:410-415

Blessing CA, Ugrinova GT, Goodson HV (2004) Actin and ARPs: action in the nucleus. Trends Cell Biol 14:435-442

Bohnsack MT, Stuven T, Kuhn C, Cordes VC, Gorlich D (2006) A selective block of nuclear actin export stabilizes the giant nuclei of Xenopus oocytes. Nat Cell Biol 8:257-263

Bretschneider T, Diez S, Anderson K, Heuser J, Clarke M, MullerTaubenberger A, Kohler J, Gerisch G (2004) Dynamic actin patterns and Arp2/3 assembly at the substrate-attached surface of motile cells. Curr Biol 14:1-10

Buckley IK, Porter KR (1967) Cytoplasmic fibrils in living cultured cells. A light and electron microscope study. Protoplasma 64:349-380

Carballido-Lopez R (2006) The bacterial actin-like cytoskeleton. Microbiol Mol Biol Rev 70:888-909

Clark TG, Merriam RW (1977) Diffusible and bound actin nuclei of Xenopus laevis oocytes. Cell 12:883-891

Clark TG, Rosenbaum JL (1979) An actin filament matrix in hand-isolated nuclei of $X$. laevis oocytes. Cell 18:1101-1108

Doyon Y, Selleck W, Lane WS, Tan S, Cote J (2004) Structural and functional conservation of the NuA4 histone acetyltransferase complex from yeast to humans. Mol Cell Biol 24:1884-1896

Egly JM, Miyamoto NG, Moncollin V, Chambon P (1984) Is actin a transcription initiation factor for RNA polymerase B? EMBO J 3:2363-2371

Eichinger L, Pachebat JA, Glockner G, Rajandream MA, Sucgang R, Berriman M, Song J, Olsen R, Szafranski K, Xu Q et al (2005) 
The genome of the social amoeba Dictyostelium discoideum. Nature 435:43-57

Franke WW (2004) Actin's many actions start at the genes. Nat Cell Biol 6:1013-1014

Gall JG (2006) Exporting actin. Nat Cell Biol 8:205-207

Gard DL (1999) Confocal microscopy and 3-D reconstruction of the cytoskeleton of Xenopus oocytes. Microsc Res Tech 44:388-414

Gonsior SM, Platz S, Buchmeier S, Scheer U, Jockusch BM, Hinssen H (1999) Conformational difference between nuclear and cytoplasmic actin as detected by a monoclonal antibody. J Cell Sci 112(Pt 6):797-809

Grummt I (2006) Actin and myosin as transcription factors. Curr Opin Genet Dev 16:191-196

Habazettl J, Gondol D, Wiltscheck R, Otlewski J, Schleicher M, Holak TA (1992) Structure of hisactophilin is similar to interleukin-1 beta and fibroblast growth factor. Nature 359:855-858

Halliburton WD (1887) On muscle-plasma. J Physiol 8:133-202

Harata M, Zhang Y, Stillman DJ, Matsui D, Oma Y, Nishimori K, Mochizuki R (2002) Correlation between chromatin association and transcriptional regulation for the Act3p/Arp4 nuclear actinrelated protein of Saccharomyces cerevisiae. Nucleic Acids Res 30:1743-1750

Hatano S, Oosawa F (1966a) Isolation and characterization of plasmodium actin. Biochim Biophys Acta 127:488-498

Hatano S, Oosawa F (1966b) Extraction of an actin-like protein from the plasmodium of a myxomycete and its interaction with myosin A from rabbit striated muscle. J Cell Physiol 68:197-202

Hatano S, Tazawa M (1968) Isolation, purification and characterization of myosin B from myxomycete plasmodium. Biochim Biophys Acta 154:507-519

Hofmann W, Reichart B, Ewald A, Muller E, Schmitt I, Stauber RH, Lottspeich F, Jockusch BM, Scheer U, Hauber J, Dabauvalle MC (2001) Cofactor requirements for nuclear export of Rev response element (RRE)- and constitutive transport element (CTE)-containing retroviral RNAs. An unexpected role for actin. J Cell Biol 152:895-910

Hofmann WA, Stojiljkovic L, Fuchsova B, Vargas GM, Mavrommatis E, Philimonenko V, Kysela K, Goodrich JA, Lessard JL, Hope TJ et al (2004) Actin is part of pre-initiation complexes and is necessary for transcription by RNA polymerase II. Nat Cell Biol 6:1094-1101

Huxley HE (1973) Muscular contraction and cell motility. Nature 243:445-449

Jockusch BM, Brown DF, Rusch HP (1971) Synthesis and some properties of an actin-like nuclear protein in the slime mold Physarum polycephalum. J Bacteriol 108:705-714

Jockusch BM, Becker M, Hindennach I, Jockusch E (1974) Slime mould actin: homology to vertebrate actin and presence in the nucleus. Exp Cell Res 89:241-246

Jockusch BM, Schoenenberger CA, Stetefeld J, Aebi U (2006) Tracking down the different forms of nuclear actin. Trends Cell Biol 16:391-396

Jockusch BM, Murk K, Rothkegel M (2007) The profile of profilins. Rev Physiol Biochem Pharmacol 159:131-149

Kiselar JG, Mahaffy R, Pollard TD, Almo SC, Chance MR (2007) Visualizing Arp2/3 complex activation mediated by binding of ATP and WASp using structural mass spectrometry. Proc Natl Acad Sci USA 104:1552-1557

Kiseleva E, Drummond SP, Goldberg MW, Rutherford SA, Allen TD, Wilson KL (2004) Actin- and protein-4.1-containing filaments link nuclear pore complexes to subnuclear organelles in Xenopus oocyte nuclei. J Cell Sci 117:2481-2490

Koestler SA, Auinger S, Vinzenz M, Rottner K, Small JV (2008) Differentially oriented populations of actin filaments generated in lamellipodia collaborate in pushing and pausing at the cell front. Nat Cell Biol 10:306-313
Koppensteiner WA, Lackner P, Wiederstein M, Sippl MJ (2000) Characterization of novel proteins based on known protein structures. J Mol Biol 296:1139-1152

Korn ED (1982) Actin polymerization and its regulation by proteins from nonmuscle cells. Physiol Rev 62:672-737

Krauss SW, Chen C, Penman S, Heald R (2003) Nuclear actin and protein 4.1: essential interactions during nuclear assembly in vitro. Proc Natl Acad Sci USA 100:10752-10757

Kuehne W (1859) Untersuchungen über Bewegungen und Veränderungen der contractilen Substanzen. Archiv für Anatomie. Physiologie und wissenschaftliche Medicin Jahrgang 1859:748-835

Lane NJ (1969) Intranuclear fibrillar bodies in actinomycin D-treated oocytes. J Cell Biol 40:286-291

Lestourgeon WM, Forer A, Yang YZ, Bertram JS, Pusch HP (1975) Contractile proteins. Major components of nuclear and chromosome non-histone proteins. Biochim Biophys Acta 379:529-552

Libotte T, Zaim H, Abraham S, Padmakumar VC, Schneider M, Lu W, Munck M, Hutchison C, Wehnert M, Fahrenkrog B et al (2005) Lamin A/C-dependent localization of Nesprin-2, a giant scaffolder at the nuclear envelope. Mol Biol Cell 16:3411-3424

Liu C, Gaspar JA, Wong HJ, Meiering EM (2002) Conserved and nonconserved features of the folding pathway of hisactophilin, a betatrefoil protein. Protein Sci 11:669-679

McAlister LE, Allison VF, Jeter JR, Nations C (1977) High-density induction of a quiescent cell state in Physarum polycephalum. J Cell Sci 25:179-190

McDonald D, Carrero G, Andrin C, de Vries G, Hendzel MJ (2006) Nucleoplasmic beta-actin exists in a dynamic equilibrium between low-mobility polymeric species and rapidly diffusing populations. J Cell Biol 172:541-552

Millonig R, Salvo H, Aebi U (1988) Probing actin polymerization by intermolecular cross-linking. J Cell Biol 106:785-796

Mommaerts WF (1992) Who discovered actin? Bioessays 14:57-59

Muller J, Oma Y, Vallar L, Friederich E, Poch O, Winsor B (2005) Sequence and comparative genomic analysis of actin-related proteins. Mol Biol Cell 16:5736-5748

Nunez E, Kwon YS, Hutt KR, Hu Q, Cardamone MD, Ohgi KA, Garcia-Bassets I, Rose DW, Glass CK, Rosenfeld MG, Fu XD (2008) Nuclear receptor-enhanced transcription requires motor- and LSD1-dependent gene networking in interchromatin granules. Cell 132:996-1010

Ohnishi T (1962) Interaction between adenosine triphosphate and potassium chloride-soluble proteins of sea urchin eggs. J Biochem 52:145-147

Ohnishi T, Kawamura H, Yamamoto T (1963) Extraction of a protein resembling actin from the cell nucleus of the calf thymus. J Biochem 54:298-300

Olave IA, Reck-Peterson SL, Crabtree GR (2002) Nuclear actin and actin-related proteins in chromatin remodeling. Annu Rev Biochem 71:755-781

Peche V, Shekar S, Leichter M, Korte H, Schroder R, Schleicher M, Holak TA, Clemen CS, Ramanath YB, Pfitzer G et al (2007) CAP2, cyclase-associated protein 2 , is a dual compartment protein. Cell Mol Life Sci 64:2702-2715

Pederson T, Aebi U (2002) Actin in the nucleus: what form and what for? J Struct Biol 140:3-9

Pederson T, Aebi U (2005) Nuclear actin extends, with no contraction in sight. Mol Biol Cell 16:5055-5060

Pendleton A, Pope B, Weeds A, Koffer A (2003) Latrunculin B or ATP depletion induces cofilin-dependent translocation of actin into nuclei of mast cells. J Biol Chem 278:14394-14400

Percipalle P, Farrants AK (2006) Chromatin remodelling and transcription: be-WICHed by nuclear myosin 1. Curr Opin Cell Biol 18:267-274

Percipalle P, Visa N (2006) Molecular functions of nuclear actin in transcription. J Cell Biol 172:967-971 
Percipalle P, Zhao J, Pope B, Weeds A, Lindberg U, Daneholt B (2001) Actin bound to the heterogeneous nuclear ribonucleoprotein hrp36 is associated with Balbiani ring mRNA from the gene to polysomes. J Cell Biol 153:229-236

Percipalle P, Jonsson A, Nashchekin D, Karlsson C, Bergman T, Guialis A, Daneholt B (2002) Nuclear actin is associated with a specific subset of hnRNP A/B-type proteins. Nucleic Acids Res 30:1725-1734

Pestic-Dragovich L, Stojiljkovic L, Philimonenko AA, Nowak G, Ke Y, Settlage RE, Shabanowitz J, Hunt DF, Hozak P, de Lanerolle $\mathrm{P}$ (2000) A myosin I isoform in the nucleus. Science 290:337-341

Pollard TD (1981) Cytoplasmic contractile proteins. J Cell Biol 91:156s-165 s

Pollard TD, Weihing RR (1974) Actin and myosin and cell movement. CRC Crit Rev Biochem 2:1-65

Rando OJ, Zhao K, Crabtree GR (2000) Searching for a function for nuclear actin. Trends Cell Biol 10:92-97

Rimm DL, Pollard TD (1989) Purification and characterization of an Acanthamoeba nuclear actin-binding protein. J Cell Biol 109:585-591

Scheer U, Hinssen H, Franke WW, Jockusch BM (1984) Microinjection of actin-binding proteins and actin antibodies demonstrates involvement of nuclear actin in transcription of lampbrush chromosomes. Cell 39:111-122

Schleicher M, Andre E, Hartmann H, Noegel AA (1988) Actin-binding proteins are conserved from slime molds to man. Dev Genet 9:521-530
Schoenenberger CA, Buchmeier S, Boerries M, Sutterlin R, Aebi U, Jockusch BM (2005) Conformation-specific antibodies reveal distinct actin structures in the nucleus and the cytoplasm. J Struct Biol 152:157-168

Shumaker DK, Kuczmarski ER, Goldman RD (2003) The nucleoskeleton: lamins and actin are major players in essential nuclear functions. Curr Opin Cell Biol 15:358-366

Smith SS, Kelly KH, Jockusch BM (1979) Actin co-purifies with RNA polymerase II. Biochem Biophys Res Commun 86:161-166

Stuven T, Hartmann E, Gorlich D (2003) Exportin 6: a novel nuclear export receptor that is specific for profilin-actin complexes. Embo J 22:5928-5940

Szent-Gyorgyi AG (2004) The early history of the biochemistry of muscle contraction. J Gen Physiol 123:631-641

Szerlong H, Saha A, Cairns BR (2003) The nuclear actin-related proteins Arp7 and Arp9: a dimeric module that cooperates with architectural proteins for chromatin remodeling. EMBO J 22:31753187

Tilney LG (1975) The role of actin in nonmuscle cell motility. Soc Gen Physiol Ser 30:339-388

Wada A, Fukuda M, Mishima M, Nishida E (1998) Nuclear export of actin: a novel mechanism regulating the subcellular localization of a major cytoskeletal protein. EMBO J 17:1635-1641

Winder SJ, Ayscough KR (2005) Actin-binding proteins. J Cell Sci 118:651-654

Worman HJ, Gundersen GG (2006) Here come the SUNs: a nucleocytoskeletal missing link. Trends Cell Biol 16:67-69 